\title{
Role of "Cancer Stem Cells" and Cell Survival in Tumor Development and Maintenance
}

\author{
J.M Adams, P.N. Kelly, A. Dakic, S. Carotta, S.L. NutT, \\ AND A. STRASSER \\ Walter \& Eliza Hall Institute of Medical Research, Melbourne 3050, Australia
}

\begin{abstract}
One critical issue for cancer biology is the nature of the cells that drive the inexorable growth of malignant tumors. Reports that only rare cell populations within human leukemias seeded leukemia in mice stimulated the now widely embraced hypothesis that only such "cancer stem cells" maintain all tumor growth. However, the mouse microenvironment might instead fail to support the dominant human tumor cell populations. Indeed, on syngeneic transplantation of mouse lymphomas and leukemias, we and other investigators have found that a substantial proportion $(>10 \%)$ of their cells drive tumor growth. Thus, dominant clones rather than rare cancer stem cells appear to sustain many tumors. Another issue is the role of cell survival in tumorigenesis. Because tumor development can be promoted by the overexpression of prosurvival genes such as $b c l-2$, we are exploring the role of endogenous Bcl-2-like proteins in lymphomagenesis. The absence of endogenous Bcl-2 in mice expressing an $\mathrm{E} \mu-m y c$ transgene reduced mature B-cell numbers and enhanced their apoptosis, but unexpectedly, lymphoma development was undiminished or even delayed. This suggests that these tumors originate in an earlier cell type, such as the pro-B or pre-B cell, and that the nascent neoplastic clones do not require Bcl-2 but may instead be protected by a Bcl-2 relative.
\end{abstract}

We address here two issues relevant to tumor development and maintenance. The first concerns the nature of the cells that perpetuate a tumor. It is now well established that normal tissues that turn over, such as the blood or gut, are sustained by rare tissue stem cells (see Weissman; Visvader et al.; both this volume). That principle stimulated the notion that the relentless growth of a tumor might be sustained not by most of its cells, but instead exclusively by a rare subpopulation, commonly termed the "cancer stem cells" (Wang and Dick 2005; Clarke et al. 2006). As reviewed recently (Clarke et al. 2006; Campbell and Polyak 2007; Adams and Strasser 2008; Vermeulen et al. 2008), this issue is attracting enormous interest, both because of its fundamental importance for tumor biology and its implications for therapy. We have investigated this issue for mouse hematopoietic tumors (Kelly et al. 2007a).

The second issue we address concerns the role of endogenous prosurvival members of the Bcl-2 family in tumorigenesis. Abatement of apoptosis is a key step in tumor development (Hanahan and Weinberg 2000; Cory and Adams 2002), and these proteins are the principal guardians against apoptosis (Adams and Cory 2007; Youle and Strasser 2008). Because overexpression of Bcl-2 can promote lymphoma development (Strasser et al. 1990), we have explored whether endogenous Bcl-2 is required for lymphomagenesis (Kelly et al. 2007b).

\section{NATURE OF THE CELLS MAINTAINING THE INEXORABLE GROWTH OF TUMORS}

\section{Two Distinct Models for Tumor Propagation}

As reviewed recently by us (Adams and Strasser 2008) and others (Wang and Dick 2005; Campbell and Polyak 2007; Vermeulen et al. 2008), two distinct models have been proposed to account for both the heterogeneity within a tumor and its inexorable growth. In the cancer stem cell model (Fig. 1A), tumor growth, like normal tissue development, relies exclusively on rare stem cells within it, and the vast majority of the cells, derived by differentiation from the cancer stem cells, lack self-renewal potential and hence do not contribute significantly to its perpetuation (Wang and Dick 2005; Clarke et al. 2006). Heterogeneity within the tumor is ascribed to somewhat aberrant differentiation from the cancer stem cell. In an alternative view (Fig. 1B), sometimes termed the "stochastic" (Wang and Dick 2005) or "clonal evolution model" (Campbell and Polyak 2007), most of the tumor cells contribute to tumor maintenance, albeit perhaps to varying degrees. This model ascribes tumor heterogeneity not only to differentiation, but also to intraclonal genetic and epigenetic variation plus microenvironmental influences. It envisions that a tumor is composed of subclones at different stages of neoplastic progression, each having a variable growth and survival advantage over normal cells.

The cancer stem cell model is thus highly hierarchical with a unique self-renewing cell type at the apex, whereas the clonal evolution model attributes much of the intratumor variation to subclonal differences in the mutational profile, and all except the terminally differentiated cells may well have some self-renewal capacity. Accordingly, in the cancer stem cell model, a phenotypically distinct and generally rare cell type maintains the tumor's growth, whereas in the clonal evolution model, the dominant subclone(s) sustains it.

Considerable confusion in the field has resulted because the term "cancer stem cell" is often also used to designate the normal cell in which the process of neoplastic transformation first began (the "cell of origin"). We follow here the current consensus that the term be restricted to the cell that maintains an established tumor 
A Cancer Stem Cell Model

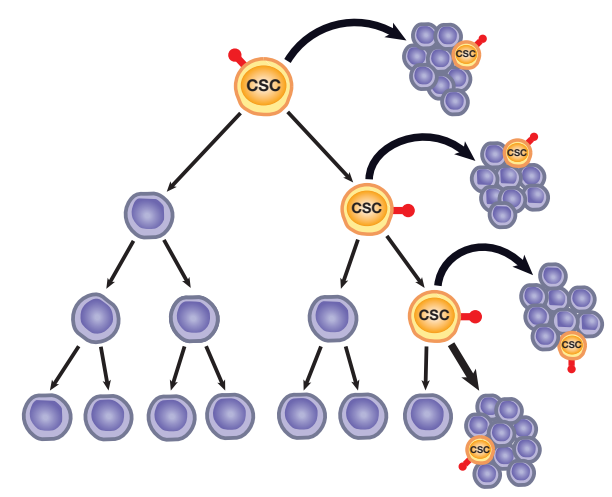

B Clonal Evolution Model

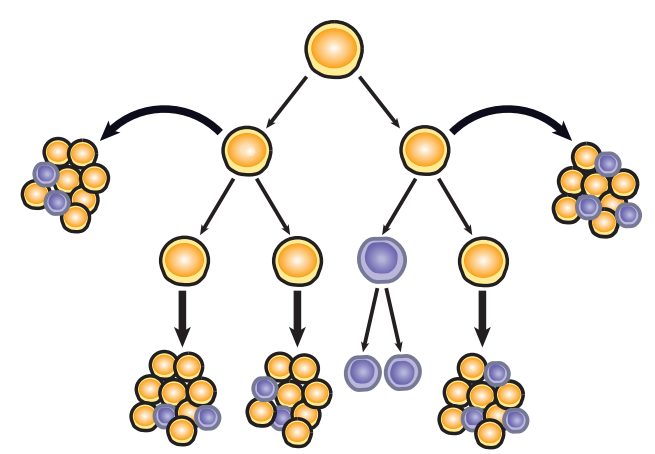

Figure 1. Models for the nature of sustained tumor growth. (A) In the cancer stem cell (CSC) model, only the CSC (gold), which can be isolated prospectively by surface markers $(r e d)$, possesses self-renewal activity and hence represents the only relevant target for therapy. $(B)$ In the clonal evolution model, a substantial proportion of the tumor cells ( gold) can sustain its growth and hence therapy must attempt to eliminate all the cell types. (Modified from Adams and Strasser 2008.)

(Clarke et al. 2006). However, for clarity we often use more operational terms such as "tumor growth-sustaining," "tumor propagating," or "tumor perpetuating" cell.

\section{Concerns about Xenotransplantation}

The cancer stem cell model has arisen primarily from studies in which human tumor cells are transplanted at limit dilution into sublethally irradiated immunodeficient mice (Clarke et al. 2006). Support for this model was greatly stimulated by reports that only 1 in $10^{4}$ to $10^{7}$ of the cells in human acute myeloid leukemia (AML) could elicit leukemia in nonobese diabetic-severe combined immunodeficient (NOD-SCID) mice (Bonnet and Dick 1997; Wang and Dick 2005). As reviewed recently (Vermeulen et al. 2008; Visvader and Lindeman 2008), similar experiments have subsequently revealed putative cancer stem cell populations in diverse human solid tumors, including those of breast, colon, and brain origin (see, e.g., Al-Hajj et al. 2003; Singh et al. 2004; Ricci-Vitiani et al. 2007).

In our view, however, the interpretation of xenotransplantation experiments is problematic. First, it is now accepted that the growth of tumor cells requires an intricate network of interactions with different support cells, including fibroblasts, endothelial cells, macrophages, mast cells, and mesenchymal stem cells (Hanahan and Weinberg 2000), and many of the cytokines and receptors mediating these two-way interactions are incompatible between mice and humans (Arai et al. 1990). Second, whether many human tumor cells can home efficiently to an appropriate niche in the mouse is unknown. Third, the irradiation of the mice will kill may of the cells needed for an inflammatory response, which can aid tumor development (Lin and Karin 2007) and presumably also tumor engraftment. Finally, the natural killer cells remaining in NOD-SCID mice may eliminate some human tumor cell populations (Kong et al. 2008). Illustrating the limitations of xenotransplantation, $50 \%$ of human AML samples did not engraft irradiated NOD-SCID mice even when $10^{7}$ or $10^{8}$ cells were introduced (Pearce et al. 2006).
Proponents of the cancer stem cell hypothesis consider that the model is proven for human AML by evidence that cell populations prospectively isolated from the leukemia samples by surface markers (e.g., CD $34^{+} \mathrm{CD} 38^{-}$) seed leukemia in mice, whereas the majority cell population lacking that phenotype does not (Bonnet and Dick 1997; Wang and Dick 2005; Clarke et al. 2006). The hidden premise in this argument, however, is that the observed differences in engraftment must reflect differences in selfrenewal ability within the patients. The nontransplantable human AML cell population might instead simply lack a feature needed for obtaining stromal support in the foreign microenvironment, such as a cytokine receptor responsive to mouse factors or a chemokine receptor that attracts the cells to a nurturing niche. Conversely, the transplantable population may simply have inadvertently acquired (perhaps by epigenetic changes) features that allow those cells to survive in the mouse milieu.

\section{Abundant Transplantable Cells in Many Mouse Hematopoietic Tumors}

To test the cancer stem cell hypothesis without the many complexities associated with xenotransplantation, we studied syngeneic transfers of cells from three types of primary mouse lymphomas or leukemias (Kelly et al. 2007a): the pre-B or B lymphomas arising in E $\mu-m y c$ transgenic mice (Adams et al. 1985), T lymphomas of E $\mu-$ $\mathrm{N}$-ras transgenic mice (Haupt et al. 1992), and the AML that develops in animals lacking PU.1 (Metcalf et al. 2006). These well-characterized models involve genes implicated in analogous human tumors, and the monoclonal tumors arise stochastically due to acquisition of mutations in other cancer-causing genes. Pertinently, cells from the preneoplastic animals do not seed tumors in recipients (Langdon et al. 1986).

The tumors in these models are relatively homogeneous, but small subpopulations of E $\mu-m y c$ lymphoma cells bore potential "stem cell" markers such as AA4.1 and Sca-1 (Fig. 2), so we included an AA4. $1^{+} / \mathrm{Sca}-1^{+}$subpopulation in 
A

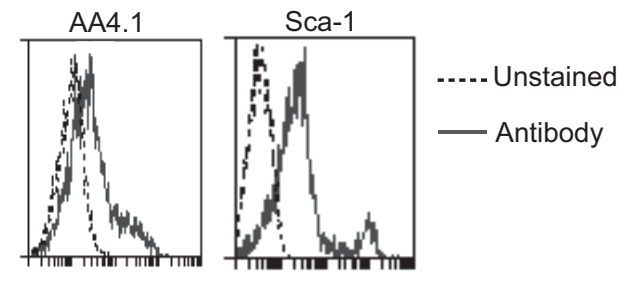

\section{B}

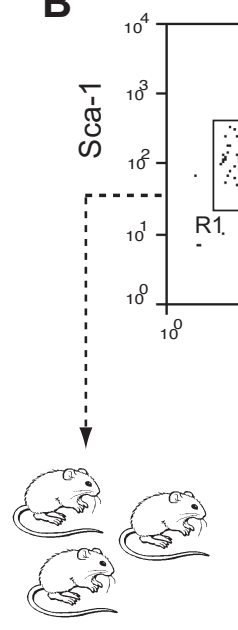

R1: Sca-1 ${ }^{+}$AA4.1 ${ }^{\text {lo }}$

one transplantation test. For the tests, we intravenously injected graded numbers of the lymphoma or leukemia cells into unmanipulated (e.g., nonirradiated) syngeneic mice and monitored tumor development (Kelly et al. 2007a).

Remarkably, ten cells from each B lymphoma sufficed to seed tumor growth, and the presence or absence of the presumptive stem cell marker made no difference (Table 1). Notably, with one B lymphoma (case 2), even transfer of a single cell (microscopically verified) succeeded in three of eight attempts. Similarly, ten cells sufficed with the T lymphoma, as well as with three of four of the AML cases (Table 1). The phenotypes of the tumors in the recipients mirrored those in the donors (Kelly et al. 2007a).

More recently, a model of pre-B acute lymphocytic leukemia (ALL) has been developed in animals whose Blineage cells lack both PU.1 and IRF-8 (S. Carotta and S.L. Nutt, unpubl.). As few as ten of the ALL cells could seed leukemia in recipients. Thus, in all four types of primary uncultured murine hematopoietic tumors that we have studied, a substantial proportion of the tumor cells $(>10 \%)$, rather than a rare subpopulation, drives tumor growth.

Several other recent studies with mouse leukemias have also demonstrated a high proportion of tumor-propagating cells. Pertinent to human AML, transplantation of colonies of mouse hematopoietic cells transformed by the MLL-AF9 oncogene, which has been generated by chromosome translocation in some human AML patients, revealed that a quarter of all the myeloid cells could seed leukemia in recipients (Somervaille and Cleary 2006). Notably, the leukemia-propagating cells had a mature $\left(\mathrm{Mac}-1^{+} \mathrm{Gr}-1^{+}\right)$phenotype, rather than that of a hematopoietic stem or early progenitor cell. Similarly, in another MLL-AF9 model, up to $50 \%$ of granulocytemacrophage progenitors could initiate leukemia (Krivtsov et al. 2006). Furthermore, in pre-B ALL produced by the BCR-ABL translocation product in ARF

Figure 2. Subpopulations of cells in E $\mu-m y c$ B lymphomas express progenitor markers. (A) Flow cytometry of cells stained with monoclonal antibodies to the surface markers AA4.1 and Sca-1, which are found on primitive hematopoietic cells (among others), revealed small subpopulations bearing these markers but not others examined (c-Kit, CD43, CD44, CD71). (B) Cells with the phenotype Sca- $1^{+} \mathrm{AA} 4.1^{\mathrm{hi}}$ and Sca- $1^{+} \mathrm{AA} 4.1^{\text {lo }}$ were purified as indicated for transplantation tests.

Table 1. A substantial proportion of tumor cells can sustain the growth of murine lymphoid and myeloid malignancies

\begin{tabular}{|c|c|c|c|c|}
\hline \multirow[b]{2}{*}{ Tumor model } & \multicolumn{4}{|c|}{ Cell number injected (days to sacrifice) } \\
\hline & $10^{5}$ & $10^{3}$ & $10^{2 \mathrm{a}}$ & 10 \\
\hline \multicolumn{5}{|l|}{ 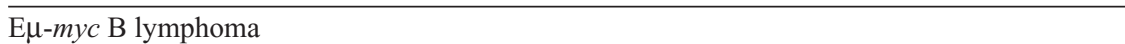 } \\
\hline Case 1 & $3 / 3(25)$ & $3 / 3(25)$ & $3 / 3(32)$ & $2 / 2(35)$ \\
\hline Case 2 & $3 / 3(21)$ & $3 / 3(23)$ & $3 / 3(24)$ & $3 / 3(24)$ \\
\hline Case $3-$ Sca $1^{+} \mathrm{AA} 4.1^{\mathrm{hi}}$ & $3 / 3(21)$ & $3 / 3(21)$ & n.d. & $3 / 3(17)$ \\
\hline- Sca- $1^{+}$AA4.1/1 $1^{\text {lo }}$ & $2 / 2(17)$ & $2 / 2(28)$ & $2 / 2(28)$ & $2 / 2(40)$ \\
\hline \multicolumn{5}{|l|}{ E $\mu-N$-ras T lymphoma } \\
\hline Case 1 & $3 / 3(28)$ & $3 / 3(42)$ & $3 / 3(28)$ & $3 / 3(28)$ \\
\hline \multicolumn{5}{|l|}{ PU.1 $1^{-/-}$AML } \\
\hline Case 1 & $1 / 1(54)$ & $2 / 2(168)$ & $1 / 2(192)$ & $0 / 2$ \\
\hline Case 2 & $2 / 2(84)$ & $2 / 2(85)$ & $2 / 2(224)$ & $1 / 2(114)$ \\
\hline Case 3 & $1 / 1(85)$ & $2 / 2(62)$ & $2 / 2(69)$ & $2 / 2(90)$ \\
\hline Case 4 & $1 / 1(30)$ & $1 / 1(37)$ & $2 / 2(79)$ & $2 / 2(88)$ \\
\hline
\end{tabular}

Cells from primary tumors of the indicated models, all on a C57BL/6 (Ly5.2) background, were mixed with $10^{6}$ congenic spleen cells as carriers and injected into nonirradiated congenic (Ly5.1) recipients. Shown are the fraction of recipients that developed tumors and the average time (in days) from transplantation to tumor development. (Reprinted, with permission, from Kelly et al. 2007a [๑ AAAS].)

${ }^{a}$ n.d. indicates not determined. 
null mice, as few as 20 of the leukemia cells, and virtually all colonies generated by them, could seed leukemia in recipients (Williams et al. 2007). Thus, in all of these cases, the leukemia-propagating cells were abundant and displayed differentiated phenotypes, rather than resembling the hematopoietic stem cell.

A high frequency of tumor-propagating cells is not confined to genetically engineered models. Pioneering studies of spontaneous mouse leukemias and lymphomas of both lymphoid and myeloid origin revealed transplantable tumor cells that ranged from more than $1 \%$ to the majority of cells, and, in several striking examples, a single cell seeded a tumor (Furth and Kahn 1937; Hewitt et al. 1976). Thus, diverse monoclonal mouse hematopoietic malignancies, including those that closely match human tumors, are sustained by a substantial proportion of their cells. These results favor a model of tumor perpetuation by dominant clone(s) (Fig. 1B), perhaps by most of the cells that can form colonies in vitro under optimal conditions, rather than exclusively by a very minor subpopulation, as expected on the cancer stem cell model (Fig. 1A).

The disparity with the human AML results indicates to us that xenotransplantation greatly underestimates the proportion of cells, and range of cell types, within the human leukemias that drive neoplastic growth. Perhaps the rare human AML cells detected by xenotransplantation founded the original disease, which may have been akin to CML (chronic myelogenous leukemia), but subsequent mutations within the clone have created a dominant, more aggressive, and mature derivative that drives the AML in patients but cannot readily engraft mice (Fig. 3). If so, xenotransplantation might be telling us about the history of the disease, rather than the cell population that now maintains it.

\section{Nature of the Cells Maintaining Solid Tumors}

The cellular differentiation pathways in most organs are much less well understood than in hematopoiesis, and solid tumor development is more complex, with greater reliance on the microenvironment and angiogenesis. In addition, these tumors often eventually escape their tissue barriers and undergo the multiple changes required for metastasis. Accordingly, as reviewed recently (Vermeulen et al. 2008; Visvader and Lindeman 2008), the analysis of stem cells in most solid tumors is generally considered less advanced than that for AML (Clarke et al. 2006). None have yet been highly purified (Al-Hajj et al. 2003; Singh et al. 2004; Ricci-Vitiani et al. 2007), and because some fall within subpopulations (e.g., CD133 ${ }^{+}$) that can contain up to $20 \%$ of the total cells, they need not be rare.

In some cases, the apparent rarity of human transplantable cells might reflect the need to cotransfer an essential support cell that happens to display similar cell surface markers. Notably, cotransfer of CD $133^{+}$support and tumor cells might explain the paradox that the colon cancer $\mathrm{CD}_{133^{+}}$population was estimated to contain 20 times more tumor-propagating cells than the unfractionated population (O'Brien et al. 2007). For example, $\mathrm{CD}_{133^{+}}$endothelial cells can enhance growth of transplanted human cancer cells (Calabrese et al. 2007). Although CD133 has been frequently used to isolate cancer stem cell populations, glioblastoma and metastatic colon carcinoma can be driven by either $\mathrm{CD}_{133^{+}}$or CD133- cells (Beier et al. 2007; Shmelkov et al. 2008). Moreover, the tumor-promoting cells within some Brca1deficient mouse mammary tumors were $\mathrm{CD} 44^{+} / \mathrm{CD} 24^{-}$, whereas others were $\mathrm{CD}_{133^{+}}$(Wright et al. 2008). Thus, cancer stem cells may not have a consistent phenotype and need not be rare.

It is also unclear whether the markers used to isolate a cancer stem cell population are intrinsic to those cells or only transiently expressed. In breast cancer development, stem cell character has been linked to the epithelial-mesenchymal transition, a step essential for metastasis (Mani et al. 2008). Cells with the phenotype of breast cancer stem cells (CD $44^{\text {hi }} / \mathrm{CD} 24^{\text {lo }}$ ) (Al-Hajj et al. 2003) were generated from immortal mammary epithelial cells by inducing an epithelial-mesenchymal transition, even simply by treatment with transforming growth factor- $\beta 1$ (TGF- $\beta 1$ ) (Mani et al. 2008). Perhaps some differentiated cells can acquire stem cell character, which in normal tissues may be induced or maintained by signals from specialized niches (Morrison and Spradling 2008).

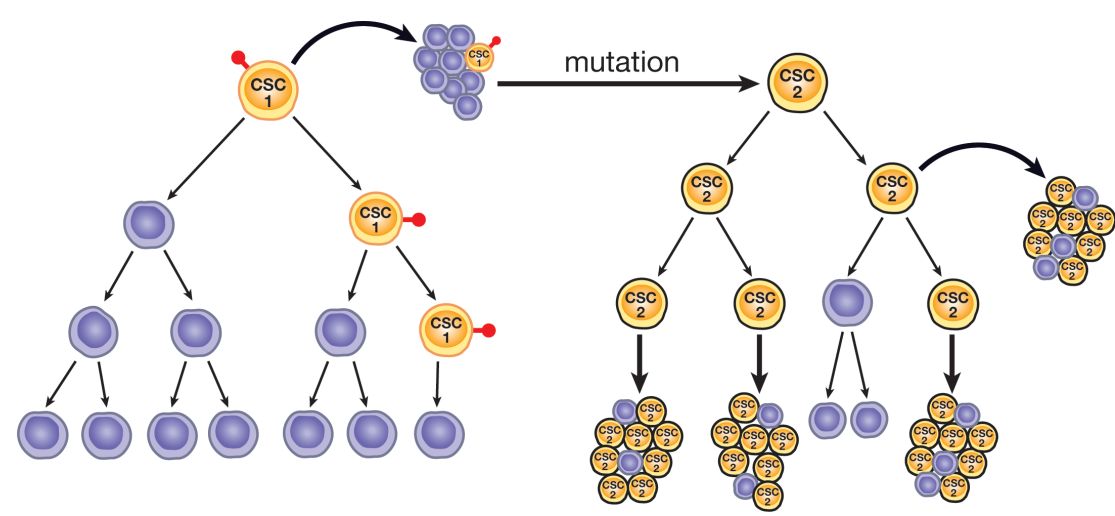

Figure 3. Clonal succession during tumor progression can create a dominant clone. At an early stage of development, a tumor might initially be driven primarily by rare cells of one phenotype (CSC1), but a mutation enhancing self-renewal in a differentiated derivative could create a dominant subclone driven by cells of a different phenotype (CSC2). In some human tumors (e.g., AML), CSC1 but not CSC2 might be able to engraft mice. (Modified from Adams and Strasser 2008.) 
Pertinently, classical studies showed that engraftment of mouse solid tumors requires far more cells than hematopoietic ones, but those numbers fell markedly on coinjection of irradiated tumor tissue, suggesting that the solid tumors rely greatly on stromal support (Hewitt et al. 1976). Such studies with human tumors might reveal additional populations of tumor-propagating cells and far higher frequencies.

\section{Implications for Tumor Propagation}

The considerations above and others in recent reviews (Campbell and Polyak 2007; Hill and Perris 2007; Shipitsin and Polyak 2008; Vermeulen et al. 2008) raise many questions about the cancer stem cell model. Certainly, the evidence summarized above that a substantial proportion of the cells in many mouse leukemias are transplantable challenges its generality. Indeed, we suggest that nearly all tumors and leukemias of lymphoid origin must be driven by a dominant clone, because all of their cells exhibit a clonotypic rearrangement of their antigen receptor genes, and that distinctive hallmark of relatively mature differentiation invariably remains in their transplants. On the other hand, as reviewed elsewhere (Adams and Strasser 2008), some of the features expected from the cancer stem cell model have appeared in three types of mouse leukemias (Huntly et al. 2004; Deshpande et al. 2006; Neering et al. 2007), one type of murine breast cancer (Cho et al. 2008), and mouse skin carcinomas (Malanchi et al. 2008).

We therefore believe that tumors most likely fall on a spectrum spanning the two models in Figure 1. Indeed, the cells driving a tumor may well change during its progression (Fig. 3). The cancer stem cell model (Fig. 1A) may represent tumors at an early stage of development, such as the chronic phase of CML, whereas the clonal evolution model (Fig. 1B) may better describe the growth of more aggressive malignancies, such as CML in blast crisis or other acute leukemias, in which the dominant clones have acquired additional oncogenic mutations (Mullighan et al. 2008; Williams and Sherr, this volume).

More compelling tests of the cancer stem cell hypothesis might be provided by analysis of more mouse tumor models; by studies with human tumors that include cotransfer of human stromal cells or irradiated tumor tissue or exploit mice installed with human support cells; and by purification of the stem cells using more specific surface markers (Barker et al. 2007). Expression profiling and genomic sequence analysis of multiple subclones from the same tumor might reveal whether heterogeneity and differences in transplantability are simply due to differentiation, as in the cancer stem cell model (Fig. 1A) or instead often reflect a varied complement of mutations, as predicted by the clonal evolution model (Fig. 1B).

Why might tumors be propagated in two different ways? Perhaps a tumor tends to follow the cancer stem cell model if the key mutation occurred in a normal stem or primitive progenitor cell, as originally suggested (Bonnet and Dick 1997), whereas the clonal evolution model predominates among tumors that originate from more differentiated cells. Alternatively, or in addition, the nature of the mutations that create the tumor may be determinative. It is also conceivable that many tumors that initially follow the cancer stem cell paradigm progress on acquiring additional mutations to resemble the clonal evolution model (Fig. 3). For example, with metastatic neuroblastoma, as few as ten cells could engraft mice and no hierarchical organization was evident (Hansford et al. 2007).

\section{Relevance to Therapy}

Much of the excitement about the cancer stem cell model has arisen from the prospect that it might provide a new approach to therapy (Wang and Dick 2005; Clarke et al. 2006). If all self-renewal capacity resided in the cancer stem cells (Fig. 1A), they would be the critical therapeutic targets, and eliminating the bulk of the cells might have negligible impact on long-term patient survival. In addition, if the stem cell subpopulation, thought to be largely quiescent, were more refractory to therapeutic agents than other tumor cell populations, those cells might be primarily responsible for relapses. Hence, it is argued that targeting the cancer stem cells might yield more durable or even curative therapies, particularly if normal stem cells can be spared. For example, imatinib has revolutionized CML management but it is not curative, perhaps because the stem cells that drive this leukemia are refractory (O'Hare et al. 2006).

Despite the promise, to date there is only limited evidence that targeting putative cancer stem cells improves therapy. The cancer stem cells are reportedly more refractory to irradiation and chemotherapy (Bao et al. 2006; Liu et al. 2006) and administration to mice of an antibody to CD44, an antigen expressed on some human AML-initiating cells, markedly reduced leukemic repopulation (Jin et al. 2006). Approaches that force all tumor cells into cycle may hold promise. The quiescence of hematopoietic stem cells and some leukemia-initiating cells requires the PML (promyelocytic leukemia) protein, and arsenic trioxide, which promotes PML degradation, can force them into cycle (Ito et al. 2008). Accordingly, this well-tolerated drug markedly enhanced the sensitivity of mouse CML cells to chemotherapy (Ito et al. 2008).

Although treatment of some tumors may benefit from targeting the stem cells, if many (perhaps most) tumors are perpetuated by dominant clones, as we have argued above, curative therapy will usually require targeting all the cell populations within a tumor.

\section{ROLE OF ENDOGENOUS BCL-2 IN MYC- INDUCED LYMPHOMA}

Impaired apoptosis is a critical step toward malignancy (Hanahan and Weinberg 2000; Cory and Adams 2002). Its role in Myc-induced tumors is well established. Enforced Myc expression not only promotes proliferation and retards differentiation but also triggers apoptosis under suboptimal growth conditions, such as limiting cytokine (Green and Evan 2002). Accordingly, in E $\mu-m y c$ transgenic mice, in which myc is expressed throughout Bcell development (Adams et al. 1985), the premalignant animals exhibit an enlarged pre-B-cell population 
(Langdon et al. 1986), but its expansion is limited by apoptosis, presumably due to consumption of the relevant cytokines. The pre-B or B-cell lymphomas that emerge stochastically have mutations that counter Myc-induced apoptosis, such as inactivation of the ARF-Mdm2-p53 pathway, which acts through the key apoptosis regulator, the Bcl-2 protein family (Adams and Cory 2007; Youle and Strasser 2008). Consequently, lymphomagenesis in E $\mu-m y c$ mice is accelerated by enforced expression of a prosurvival family member such as Bcl-2 (Strasser et al. 1990). Apoptosis ensues in such myc-bcl-2 bitransgenic tumors if $\mathrm{Bcl}-2$ expression is ablated (e.g., by Cre-loxmediated elimination of the $b c l-2$ transgene), underlining its crucial role (Letai et al. 2004).

These findings suggested that endogenous $b c l-2$ might be required for the development of E $\mu-m y c$ lymphomas, particularly because Bcl-2 is expressed in most stages of lymphopoiesis, including early progenitors ( $\mathrm{Li}$ et al. 1993), and its overexpression enhances their survival (McDonnell et al. 1989; Strasser et al. 1991). We have therefore compared tumor development in the presence and absence of endogenous Bcl-2 (Kelly et al. 2007b). To bypass the complication that young Bcl-2-deficient mice succumb to polycystic kidney disease (Veis et al. 1993), we compared wild-type mice whose hematopoietic system was reconstituted with hematopoietic stem cell populations from either $\mathrm{E} \mu-m y c / b c l-2^{-/-}$or $\mathrm{E} \mu-m y c / b c l-2^{+/+}$ (hereafter, E $\mu-m y c$ ) embryos. We will denote the reconstituted animals by the genotype of their donor cells.

\section{Preneoplastic E $\mu-m y c / b c l-2^{-/-}$Mice Have Much Fewer Mature B Cells}

To determine how the absence of Bcl-2 affected B lymphopoiesis before the recipients developed a tumor, we enumerated the B-lymphoid cells at various stages of differentiation in their hematopoietic tissues by flow cytometry. The E $\mu-m y c / b c l-2^{-/-}$bone marrow contained pro-Bcell numbers similar to $\mathrm{E} \mu-m y c$ recipients but about twofold to threefold less pre-B and $\operatorname{sIg}^{+} \mathrm{B}$ cells. Strikingly, the spleen (and lymph nodes) of E $\mu-m y c / b c l-$ $2^{-/}$recipients had less than $10 \%$ of the mature B cells in the E $\mu-m y c$ recipients (Fig. 4). Thus, endogenous Bcl-2 appears to be critical for the survival of mature $\mathrm{E} \mu-m y c \mathrm{~B}$ cells but less important for the transgenic pro-B, pre-B, and immature B cells.

\section{Bcl-2 Loss Accelerates Myc-induced Apoptosis of Mature B Cells}

To assess whether the reduction in mature B cells in $\mathrm{E} \mu-m y c / b c l-2^{-/-}$recipients reflected increased apoptosis, we purified donor-derived (Ly5. $2^{+}$) pro-B, pre-B, immature $\mathrm{B}$, and mature $\mathrm{B}$ cells from bone marrow or spleen by flow cytometry and monitored their survival when cultured without cytokine. In the absence of cytokine, deregulated myc expression enhances apoptosis of B-lymphoid cells (Strasser et al. 1996). Significantly, apoptosis was accelerated markedly in the mature $\mathrm{B}$ cells but not the pre$\mathrm{B}$ cells (or pro-B cells) from $\mathrm{E} \mu-m y c / b c l-2^{-/-}$mice (Fig. 5). Thus, endogenous Bcl-2 is critical for countering the

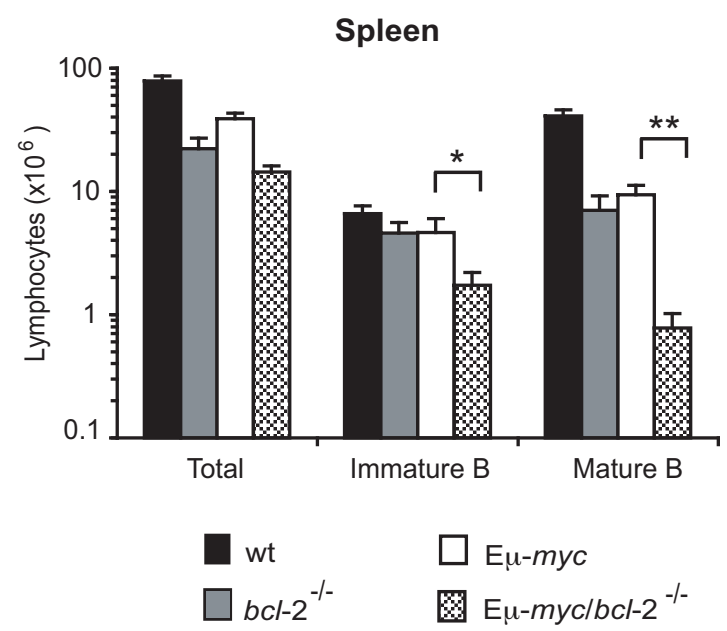

Figure 4. Preleukemic E $\mu-m y c / b c l-2^{-/-}$reconstituted mice have reduced numbers of mature B cells. Spleens were harvested from wild-type mice reconstituted with fetal liver cells of the indicated genotypes. Single-cell suspensions were stained with monoclonal antibodies to B-lineage surface markers, gated for donor-derived cells (Ly5.2), and analyzed by flow cytometry. Mean cell numbers \pm S.E.M. are shown. (*) $p<0.05 ;(* *) p$ $<0.001$. (Reprinted from Kelly et al. 2007b.)

proapoptotic impact of deregulated Myc in mature B cells but appears dispensable for pro-B- and pre-B-cell survival.

\section{Myc-induced Lymphomagenesis Is Unperturbed by Bcl-2 Loss}

The dearth of B cells in E $\mu-m y c / b c l-2^{-/-}$mice and their accelerated apoptosis in culture led us to expect reduced or delayed lymphomagenesis. Remarkably, however, tumor incidence and latency in $\mathrm{E} \mu-m y c$ and $\mathrm{E} \mu-m y c / b c l$ -

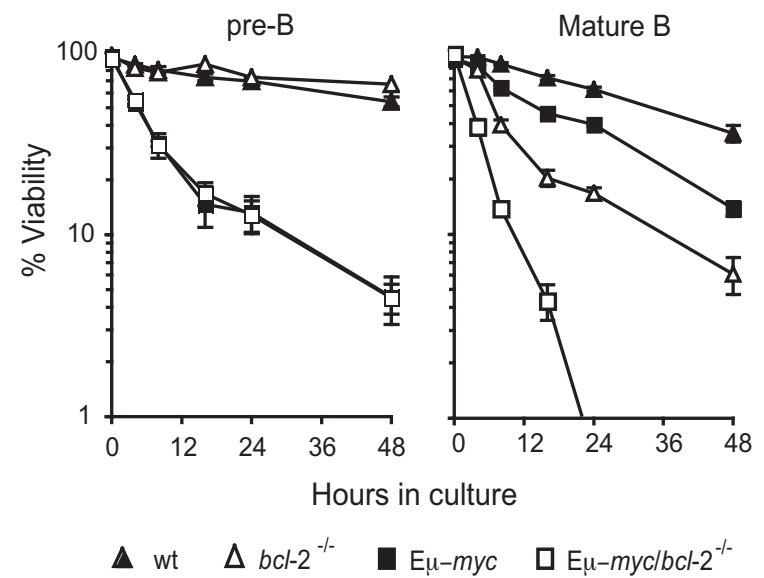

Figure 5. Accelerated apoptosis of E $\mu-m y c / b c l-2^{-/}$mature B cells in culture. Donor-derived B-cell populations, preneoplastic pre-B cells, and mature B cells from the reconstituted mice were cultured without cytokines for the indicated periods, and cell viability was measured by staining with PI plus annexin V and flow cytometry (means \pm S.E.M.). (Reprinted from Kelly et al. 2007b.) 
$2^{-/-}$reconstituted mice were indistinguishable (Fig. 6). The tumor phenotype was also the same (Kelly et al. 2007b): All were either pro/pre-B cells or immature B cells. The lymphomas were also just as aggressive, as judged from spleen enlargement, elevation of blood leukocytes, infiltration of the liver, lung, and kidney, and transplantability.

\section{Interpretation}

The failure of Bcl-2 loss to reduce the numbers of transgenic pro-B or pre-B cells in the bone marrow, or their survival when deprived of cytokine in vitro, probably reflects the low level of endogenous Bcl-2 in pre-B cells (Li et al. 1993). We surmise that other prosurvival Bcl-2 family members, such as Bcl- $\mathrm{x}_{\mathrm{L}}$, which is highly expressed in pre-B lymphocytes, are essential for inhibiting their Myc-induced apoptosis. We are therefore currently studying lymphomagenesis in the absence of $\mathrm{Bcl}-\mathrm{x}_{\mathrm{L}}$. Intriguingly, our preliminary results suggest that its loss, unlike Bcl-2 loss, greatly inhibits the tumor development (P.N. Kelly, J.M. Adams, and A. Strasser, unpubl.).

The marked deficit of mature B cells in preleukemic E $\mu$ $m y c / b c l-2^{-/-}$mice presumably reflects their enhanced susceptibility to Myc-induced apoptosis. Despite this deficit, malignancy developed as rapidly as in the E $\mu-m y c$ animals, and the tumors were just as aggressive. These results demonstrate that the survival of the mature B cells is not essential for Myc-induced lymphomagenesis or sustained lymphoma growth. We surmise that neoplastic clones in $\mathrm{E} \mu-m y c$ transgenic mice typically originate from a less mature cell type, one that does not require Bcl-2 for survival. An analogous observation is that preleukemic E $\mu$ $m y c / E \mu-\max 41$ bitransgenic mice, which have less than $1 \%$ of the normal number of B lymphocytes, develop lymphoma at a rate comparable to E $\mu-m y c$ mice (Lindeman et al. 1994). Conversely, E $\mu-m y c / E \mu-b c l-2$ bitransgenic animals exhibit copious-cycling mature $\left(\mathrm{sIg}^{+}\right)$B-lymphoid cells, but all of the tumors that arise have a very primitive ("stem-cell"-like) phenotype, and the more mature bitrans-

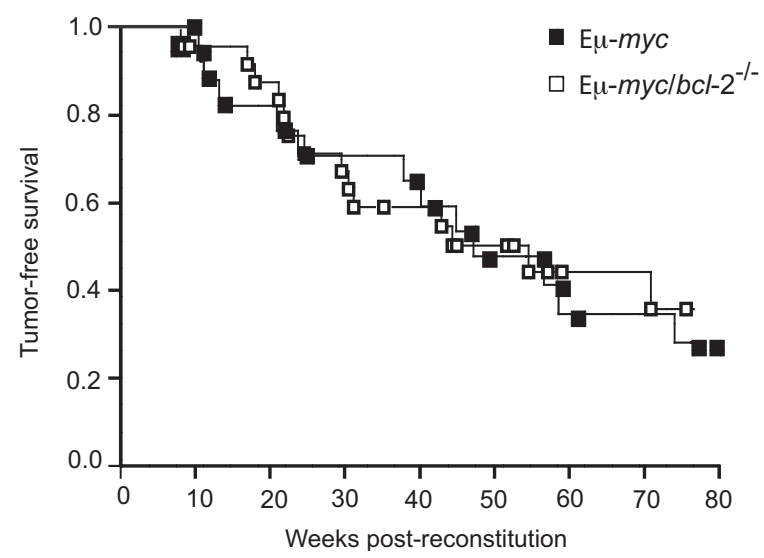

Figure 6. Loss of endogenous Bcl-2 does not delay Mycinduced lymphomagenesis. Kaplan-Meier analysis of tumorigenesis in mice reconstituted with $\mathrm{E} \mu-m y c$ and $\mathrm{E} \mu-m y c / b c l-2^{-}$ embryos. (Reprinted from Kelly et al. 2007b.) genic B cells do not elicit tumors on transplantation (Strasser et al. 1990). These observations indicate that, even though many E $\mu-m y c$ lymphomas express surface immunoglobulin, indicative of a mature phenotype, the oncogenic mutations that cooperate with Myc most likely are acquired in a primitive lymphoid progenitor.

Our finding that loss of endogenous Bcl-2 accelerated apoptosis of preneoplastic mature $\mathrm{E} \mu-m y c \mathrm{~B}$ cells, together with the demonstration that removing Bcl-2 decimated the tumors arising in $\mathrm{E} \mu-m y c / \mathrm{E} \mu-b c l-2$ mice (Letai et al. 2004), supports the concept that inactivating the function (or expression) of Bcl-2, or its close relatives, will prove to be an important new approach to therapy (Fesik 2005; Adams and Cory 2007). Indeed, in preclinical studies, the compound ABT-737 and the closely related ABT-263, which both inactivate three Bcl-2 family members (Bcl-2, Bcl- $\mathrm{x}_{\mathrm{L}}$, and $\left.\mathrm{Bcl}-\mathrm{w}\right)$, have shown considerable promise with chronic lymphocytic leukemia and several other tumor types (Oltersdorf et al. 2005; Adams and Cory 2007; Tse et al. 2008). However, our finding that endogenous Bcl-2 is not required for the sustained growth of E $\mu-m y c$ lymphomas indicates that targeting Bcl-2 alone might not be effective for this class of tumor. Targeting several Bcl-2 family members (as ABT-737 does) represents one approach, but we surmise that antagonizing a single critical prosurvival family member, such as $\mathrm{Bcl}-\mathrm{x}_{\mathrm{L}}$, offers the best prospect for selectively killing certain types of tumor cells while minimizing damage to normal tissues.

\section{CONCLUSIONS}

Our studies on transplantation of mouse hematopoietic tumors, and reports by several other groups, indicate that many such tumors are perpetuated by a substantial proportion of their neoplastic cells. These findings raise doubts about the interpretation of the xenotransplantation experiments that underpin the cancer stem cell model. We believe that model (Fig. 1A) is unlikely to appropriately represent many tumors, except perhaps at an early stage in their development (Fig. 3). Tumors that have accumulated the multiple mutations needed for full-fledged malignancy may be propagated instead by a dominant cell population (Fig. 1B). Thus, different tumors may fall on a spectrum between the cancer stem cell and clonal evolution models, or those models may represent early and late stages of tumor progression, respectively (Fig. 3). The important implication for treatment is that curative therapy is likely to require targeting not simply a rare cell population but most of the neoplastic cells found in the tumor.

Our investigation of the role of endogenous Bcl-2 in Myc-induced lymphomagenesis revealed that Bcl-2 loss caused a dramatic drop in mature B cells, presumably reflecting the Myc-induced apoptosis observed at that stage. Nevertheless, lymphoma development was unperturbed, and the tumors were just as aggressive. We conclude that the initiation, development, and continued growth of $\mathrm{E} \mu-m y c$ lymphoma does not depend on endogenous Bcl-2, nor on the total number of B-lymphoid cells driven by the E $\mu-m y c$ transgene. We surmise that a Bcl-2 
prosurvival relative, such as $\mathrm{Bcl}-\mathrm{x}_{\mathrm{L}}$, has a more critical role. The implication for therapy is that it will be important to identify, for various types of tumor, the prosurvival protein(s) required for their maintenance, because those proteins will be critical targets for intervention.

\section{ACKNOWLEDGMENTS}

We are grateful to our colleagues, in particular Drs. S. Cory, J. Visvader, G. Lindeman, D.C.S. Huang, and P. Bouillet, for advice and discussions. This work was supported by fellowships and grants from the Australian National Health and Medical Research Council (Program Grant 257502), the Leukemia and Lymphoma Society (SCOR grant 7015), and the U.S. National Cancer Institute (CA 80188 and CA 43540).

\section{REFERENCES}

Adams, J.M. and Cory, S. 2007. The Bcl-2 apoptotic switch in cancer development and therapy. Oncogene 26: 1324-1337.

Adams, J.M. and Strasser, A. 2008. Is tumour growth sustained by rare cancer stem cells or dominant clones? Cancer Res. 68: 4018-4021.

Adams, J.M., Harris, A.W., Pinkert, C.A., Corcoran, L.M., Alexander, W.S., Cory, S., Palmiter, R.D., and Brinster, R.L. 1985. The c-myc oncogene driven by immunoglobulin enhancers induces lymphoid malignancy in transgenic mice. Nature 318: 533-538.

Al-Haij, M., Wicha, M.S., Benito-Hernandez, A., Morrison, S.J., and Clarke, M.F. 2003. Prospective identification of tumorigenic breast cancer cells. Proc. Natl. Acad. Sci. 100: 39833988.

Arai, K.I., Lee, F., Miyajima, A., Miyatake, S., Arai, N., and Yokota, T. 1990. Cytokines: Coordinators of immune and inflammatory responses. Annu. Rev. Biochem. 59: 783-836.

Bao, S., Wu, Q., McLendon, R.E., Hao, Y., Shi, Q., Hjelmeland, A.B., Dewhirst, M.W., Bigner, D.D., and Rich, J.N. 2006. Glioma stem cells promote radioresistance by preferential activation of the DNA damage response. Nature 444: 756-760.

Barker, N., van Es, J.H., Kuipers, J., Kujala, P., van den Born, M., Cozijnsen, M., Haegebarth, A., Korving, J., Begthel, H., Peters, P.J., and Clevers, H. 2007. Identification of stem cells in small intestine and colon by marker gene Lgr5. Nature 449: 1003-1007.

Beier, D., Hau, P., Proescholdt, M., Lohmeier, A., Wischhusen, J., Oefner, P.J., Aigner, L., Brawanski, A., Bogdahn, U., and Beier, C.P. 2007. CD $133^{+}$and CD133- glioblastoma-derived cancer stem cells show differential growth characteristics and molecular profiles. Cancer Res. 67: 4010-4015.

Bonnet, D. and Dick, J.E. 1997. Human acute myeloid leukemia is organized as a hierarchy that originates from a primitive hematopoietic cell. Nat. Med. 3: 730-737.

Calabrese, C., Poppleton, H., Kocak, M., Hogg, T.L., Fuller, C., Hamner, B., Oh, E.Y., Gaber, M.W., Finklestein, D., Allen, M., et al. 2007. A perivascular niche for brain tumor stem cells. Cancer Cell 11: 69-82.

Campbell, L.L. and Polyak, K. 2007. Breast tumor heterogeneity: Cancer stem cells or clonal evolution? Cell Cycle 6: 2332-2338.

Cho, R.W., Wang, X., Diehn, M., Shedden, K., Chen, G.Y., Sherlock, G., Gurney, A., Lewicki, J., and Clarke, M.F. 2008. Isolation and molecular characterization of cancer stem cells in MMTV-Wnt-1 murine breast tumors. Stem Cells 26: 364-371.

Clarke, M.F., Dick, J.E., Dirks, P.B., Eaves, C.J., Jamieson, C.H., Jones, D.L., Visvader, J., Weissman, I.L., and Wahl, G.M. 2006. Cancer stem cells - Perspectives on current status and future directions: AACR Workshop on Cancer Stem Cells. Cancer Res. 66: 9339-9344.
Cory, S. and Adams, J.M. 2002. The Bcl2 family: Regulators of the cellular life-or-death switch. Nat. Rev. Cancer 2: 647-656.

Deshpande, A.J., Cusan, M., Rawat, V.P., Reuter, H., Krause, A., Pott, C., Quintanilla-Martinez, L., Kakadia, P., Kuchenbauer, F., Ahmed F., et al. 2006. Acute myeloid leukemia is propagated by a leukemic stem cell with lymphoid characteristics in a mouse model of CALM/AF10-positive leukemia. Cancer Cell 10: 363-374.

Fesik, S.W. 2005. Promoting apoptosis as a strategy for cancer drug discovery. Nat. Rev. Cancer 5: 876-885.

Furth, J. and Kahn, M.C. 1937. The transmission of leukemia in mice with a single cell. Am. J. Cancer 31: 276-282.

Green, D.R. and Evan, G.I. 2002. A matter of life and death. Cancer Cell 1: 19-30.

Hanahan, D. and Weinberg, R.A. 2000. The hallmarks of cancer. Cell 100: $57-70$.

Hansford, L.M., McKee, A.E., Zhang, L., George, R.E., Gerstle, J.T., Thorner, P.S., Smith, K.M., Look, A.T., Yeger, H., Miller, F.D., Irwin, M.S., Thiele, C.J., and Kaplan, D.R. 2007. Neuroblastoma cells isolated from bone marrow metastases contain a naturally enriched tumor-initiating cell. Cancer Res. 67: 11234-11243.

Haupt, Y., Harris, A.W., and Adams J.M. 1992. Retroviral infection accelerates $\mathrm{T}$ lymphomagenesis in $\mathrm{E} \mu-\mathrm{N}-$ ras transgenic mice by activating c-myc and N-myc. Oncogene 7: 981-986.

Hewitt, H.B., Blake, E.R. and Walder, A.S. 1976. A critique of the evidence for active host defence against cancer, based on personal studies of 27 murine tumours of spontaneous origin. Br. J. Cancer 33: 241-259.

Hill, R.P. and Perris, R. 2007. "Destemming" cancer stem cells. J. Natl. Cancer Inst. 99: 1435-1440.

Huntly, B.J., Shigematsu, H., Deguchi, K., Lee, B.H., Mizuno, S., Duclos, N., Rowan, R., Amaral, S., Curley, D., Williams, I.R., Akashi, K., and Gilliland, D.G. 2004. MOZ-TIF2, but not BCR-ABL, confers properties of leukemic stem cells to committed murine hematopoietic progenitors. Cancer Cell 6: 587-596.

Ito, K., Bernardi, R., Morotti, A., Matsuoka, S., Saglio, G., Ikeda, Y., Rosenblatt, J., Avigan, D.E., Teruya-Feldstein, J., and Pandolfi, P.P. 2008. PML targeting eradicates quiescent leukaemia-initiating cells. Nature 453: 1072-1078.

Jin, L., Hope, K.J., Zhai, Q., Smadja-Joffe, F., and Dick, J.E. 2006. Targeting of CD44 eradicates human acute myeloid leukemic stem cells. Nat. Med. 12: 1167-1174.

Kelly, P.N., Dakic, A., Adams, J.M., Nutt, S.L., and Strasser, A. 2007a. Tumor growth need not be driven by rare cancer stem cells. Science 317: 337.

Kelly, P.N., Puthalakath, H., Adams, J.M., and Strasser, A. $2007 \mathrm{~b}$. Endogenous $b c l-2$ is not required for the development of Eu-myc-induced B-cell lymphoma. Blood 109: 49074913.

Kong, Y., Yoshida, S., Saito, Y., Doi, T., Nagatoshi, Y., Fukata, M., Saito, N., Yang, S.M., Iwamoto, C., Okamura, J., et al. 2008. $\mathrm{CD} 34^{+} \mathrm{CD} 38^{+} \mathrm{CD} 19^{+}$as well as $\mathrm{CD} 34^{+} \mathrm{CD} 38^{-} \mathrm{CD} 19^{+}$ cells are leukemia-initiating cells with self-renewal capacity in human B-precursor ALL. Leukemia 22: 1207-1213.

Krivtsov, A.V., Twomey, D., Feng, Z., Stubbs, M.C., Wang, Y., Faber, J., Levine, J.E., Wang, J., Hahn, W.C., Gilliland, D.G., Golub, T.R., and Armstrong, S.A. 2006. Transformation from committed progenitor to leukaemia stem cell initiated by MLL-AF9. Nature 442: 818-822.

Langdon, W.Y., Harris, A.W., Cory, S., and Adams, J.M. 1986. The c-myc oncogene perturbs B lymphocyte development in $\mathrm{E} \mu-m y c$ transgenic mice. Cell 47: 11-18.

Letai, A., Sorcinelli, M.D., Beard, C., and Korsmeyer, S.J. 2004. Antiapoptotic BCL-2 is required for maintenance of a model leukemia. Cancer Cell 6: 241-249.

Li, Y.-S., Hayakawa, K., and Hardy, R.R. 1993. The regulated expression of B lineage associated genes during B cell differentiation in bone marrow and fetal liver. J. Exp. Med. 178: 951-960.

Lin, W.W. and Karin, M. 2007. A cytokine-mediated link between innate immunity, inflammation, and cancer. J. Clin. Invest. 117: 1175-1183. 


\section{STEM CELLS AND CELL SURVIVAL IN CANCER}

Lindeman, G.J., Adams, J.M., Cory, S., and Harris, A.W. 1994. B-lymphoid to granulocytic switch during hematopoiesis in a transgenic mouse strain. Immunity 1: 517-527.

Liu, G., Yuan, X., Zeng, Z., Tunici, P., Ng, H., Abdulkadir, I.R., Lu, L., Irvin, D., Black, K.L., and Yu, J.S. 2006. Analysis of gene expression and chemoresistance of $\mathrm{CD} 133^{+}$cancer stem cells in glioblastoma. Mol. Cancer 5: 67.

Malanchi, I., Peinado, H., Kassen, D., Hussenet, T., Metzger, D., Chambon, P., Huber, M., Hohl, D., Cano, A., Birchmeier, W., and Huelsken, J. 2008. Cutaneous cancer stem cell maintenance is dependent on $\beta$-catenin signalling. Nature 452: 650-653.

Mani, S.A., Guo, W., Liao, M.J., Eaton, E.N., Ayyanan, A., Zhou, A.Y., Brooks, M., Reinhard, F., Zhang, C.C., Shipitsin, M., Campbell, L.L., Polyak, K., Brisken, C., Yang, J., and Weinberg, R.A. 2008. The epithelial-mesenchymal transition generates cells with properties of stem cells. Cell 133: 704-715.

McDonnell, T.J., Deane, N., Platt, F.M., Nuñez, G., Jaeger, U., McKearn, J.P. and Korsmeyer, S.J. 1989. bcl-2-immunoglobulin transgenic mice demonstrate extended B cell survival and follicular lymphoproliferation. Cell 57: 79-88

Metcalf, D., Dakic, A., Mifsud, S., Di Rago, L., Wu, L., and Nutt, S. 2006. Inactivation of PU.1 in adult mice leads to the development of myeloid leukemia. Proc. Natl. Acad. Sci. 103: 1486-1491.

Morrison, S.J. and Spradling, A.C. 2008. Stem cells and niches: Mechanisms that promote stem cell maintenance throughout life. Cell 132: 598-611.

Mullighan, C.G., Miller, C.B., Radtke, I., Phillips, L.A., Dalton, J., Ma, J., White, D., Hughes, T.P., Le Beau, M.M., Pui, C.H., Relling, M.V., Shurtleff, S.A., and Downing, J.R. 2008. BCR$A B L 1$ lymphoblastic leukaemia is characterized by the deletion of Ikaros. Nature 453: 110-114.

Neering, S.J., Bushnell, T., Sozer, S., Ashton, J., Rossi, R.M., Wang, P.Y., Bell, D.R., Heinrich, D., Bottaro, A. and Jordan, C.T. 2007. Leukemia stem cells in a genetically defined murine model of blast-crisis CML. Blood 110: 2578-2585.

O'Brien, C.A., Pollett, A., Gallinger, S., and Dick, J.E. 2007. A human colon cancer cell capable of initiating tumour growth in immunodeficient mice. Nature 445: 106-110.

O'Hare, T., Corbin, A.S., and Druker, B.J. 2006. Targeted CML therapy: Controlling drug resistance, seeking cure. Curr. Opin. Genet. Dev. 16: 92-99.

Oltersdorf, T., Elmore, S.W., Shoemaker, A.R., Armstrong, R.C., Augeri, D.J., Belli, B.A., Bruncko, M., Deckwerth, T.L., Dinges, J., Hajduk, P.J., et al. 2005. An inhibitor of Bcl2 family proteins induces regression of solid tumours. Nature 435: $677-681$.

Pearce, D.J., Taussig, D., Zibara, K., Smith, L.L., Ridler, C.M., Preudhomme, C., Young, B.D., Rohatiner, A.Z., Lister, T.A., and Bonnet D. 2006. AML engraftment in the NOD/SCID assay reflects the outcome of AML: Implications for our understanding of the heterogeneity of AML. Blood 107: $1166-1173$

Ricci-Vitiani, L., Lombardi, D.G., Pilozzi, E., Biffoni, M.,
Todaro, M., Peschle, C., and De Maria, R. 2007. Identification and expansion of human colon-cancer-initiating cells. Nature 445: $111-115$.

Shipitsin, M. and Polyak, K. 2008. The cancer stem cell hypothesis: In search of definitions, markers, and relevance. $L a b$. Invest. 88: 459-463.

Shmelkov, S.V., Butler, J.M., Hooper, A.T., Hormigo, A., Kushner, J., Milde, T., St Clair, R., Baljevic, M., White, I., Jin, D.K., et al. 2008. CD133 expression is not restricted to stem cells, and both $\mathrm{CD} 133^{+}$and $\mathrm{CD} 133^{-}$metastatic colon cancer cells initiate tumors. J. Clin. Invest. 118: 2111-2120.

Singh, S.K., Hawkins, C., Clarke, I.D., Squire, J.A., Bayani, J., Hide, T., Henkelman, R.M., Cusimano, M.D., and Dirks, P.B. 2004. Identification of human brain tumour initiating cells. Nature 432: 396-401.

Somervaille, T.C. and Cleary, M.L. 2006. Identification and characterization of leukemia stem cells in murine MLL-AF9 acute myeloid leukemia. Cancer Cell 10: 257-268.

Strasser, A., Harris, A.W., Bath, M.L., and Cory, S. 1990. Novel primitive lymphoid tumours induced in transgenic mice by cooperation between $m y c$ and bcl-2. Nature 348: 331-333.

Strasser, A., Whittingham, S., Vaux, D.L., Bath, M.L., Adams, J.M., Cory, S., and Harris, A.W. 1991. Enforced BCL2 expression in B-lymphoid cells prolongs antibody responses and elicits autoimmune disease. Proc. Natl. Acad. Sci. 88: 8661-8665.

Strasser, A., Elefanty, A.G., Harris, A.W., and Cory, S. 1996. Progenitor tumours from E $\mu-b c l-2-m y c$ transgenic mice have lymphomyeloid differentiation potential and reveal developmental differences in cell survival. EMBO J. 15: 3823-3834.

Tse, C., Shoemaker, A.R., Adickes, J., Anderson, M.G., Chen, J., Jin, S., Johnson, E.F., Marsh, K.C., Mitten, M.J., Nimmer, P., et al. 2008. ABT-263: A potent and orally bioavailable Bcl-2 family inhibitor. Cancer Res. 68: 3421-3428.

Veis, D.J., Sorenson, C.M., Shutter, J.R., and Korsmeyer, S.J. 1993. Bcl-2-deficient mice demonstrate fulminant lymphoid apoptosis, polycystic kidneys, and hypopigmented hair. Cell 75: $229-240$

Vermeulen, L., Sprick, M.R., Kemper, K., Stassi, G., and Medema, J.P. 2008. Cancer stem cells-Old concepts, new insights. Cell Death Differ. 15: 947-958.

Visvader, J. and Lindeman, G.J. 2008. Cancer stem cells in solid tumours: Accumulating evidence and unresolved questions. Nat. Rev. Cancer (in press).

Wang, J.C. and Dick, J.E. 2005. Cancer stem cells: Lessons from leukemia. Trends Cell Biol. 15: 494-501.

Williams, R.T., den Besten, W., and Sherr, C.J. 2007. Cytokinedependent imatinib resistance in mouse BCR-ABL ${ }^{+}$, Arf-null lymphoblastic leukemia. Genes Dev. 21: 2283-2287.

Wright, M., Calcagno, A.M., Salcido, C.D., Carlson, M.D., Ambudkar, S.V., and Varticovski, L. 2008. Brcal breast tumors contain distinct $\mathrm{CD} 44^{+} / \mathrm{CD} 24^{-}$and $\mathrm{CD} 133^{+}$cells with cancer stem cell characteristics. Breast Cancer Res. 10: R10.

Youle, R.J. and Strasser, A. 2008. The BCL-2 protein family: Opposing activities that mediate cell death. Nat. Rev. Mol. Cell Biol. 9: 47-59. 


\title{
$\$_{\mathrm{CSH}}^{\infty} \mathrm{C}$ Cold Spring Harbor Symposia SYMPOSIA
}

\section{Role of "Cancer Stem Cells" and Cell Survival in Tumor Development and Maintenance}

\author{
J.M Adams, P.N. Kelly, A. Dakic, et al.
}

Cold Spring Harb Symp Quant Biol 2008 73: 451-459 originally published online November 6, 2008 Access the most recent version at doi:10.1101/sqb.2008.73.004

References This article cites 62 articles, 15 of which can be accessed free at: http://symposium.cshlp.org/content/73/451.full.html\#ref-list-1

\section{License}

Email Alerting Receive free email alerts when new articles cite this article - sign up in the Service box at the top right corner of the article or click here. 